\title{
Gas properties of winter lake ice in Northern Sweden: implication for carbon gas release
}

\author{
T. Boereboom ${ }^{1}$, M. Depoorter ${ }^{1, *}$, S. Coppens ${ }^{1}$, and J.-L. Tison ${ }^{1}$ \\ ${ }^{1}$ Laboratoire de Glaciologie, Université Libre de Bruxelles, Belgium \\ *now at: Bristol Glaciology Centre, University of Bristol, UK
}

Correspondence to: T. Boereboom (thierry.boereboom@ulb.ac.be)

Received: 14 September 2011 - Published in Biogeosciences Discuss.: 27 September 2011

Revised: 31 January 2012 - Accepted: 8 February 2012 - Published: 20 February 2012

\begin{abstract}
This paper describes gas composition, total gas content and bubbles characteristics in winter lake ice for four adjacent lakes in a discontinuous permafrost area. Our gas mixing ratios for $\mathrm{O}_{2}, \mathrm{~N}_{2}, \mathrm{CO}_{2}$, and $\mathrm{CH}_{4}$ suggest that gas exchange occurs between the bubbles and the water before entrapment in the ice. Comparison between lakes enabled us to identify 2 major "bubbling events" shown to be related to a regional drop of atmospheric pressure. Further comparison demonstrates that winter lake gas content is strongly dependent on hydrological connections: according to their closed/open status with regards to water exchange, lakes build up more or less greenhouse gases (GHG) in their water and ice cover during the winter, and release it during spring melt. These discrepancies between lakes need to be taken into account when establishing a budget for permafrost regions. Our analysis allows us to present a new classification of bubbles, according to their gas properties. Our methane emission budgets (from $6.5210^{-5}$ to $12.7 \mathrm{mg} \mathrm{CH}_{4} \mathrm{~m}^{-2} \mathrm{~d}^{-1}$ at 4 different lakes) for the three months of winter ice cover is complementary to other budget estimates, as our approach encompasses inter- and intra-lake variability.

Most available studies on boreal lakes have focused on quantifying GHG emissions from sediment by means of various systems collecting gases at the lake surface, and this mainly during the summer "open water" period. Only few of these have looked at the gas enclosed in the winter ice-cover itself. Our approach enables us to integrate, for the first time, the history of winter gas emission for this type of lakes.
\end{abstract}

\section{Introduction}

Lakes in subarctic environments are affected by and contribute to the current global warming. In permafrost areas, lakes are net emitters of methane and carbon dioxide, two greenhouse gases (GHG). Lakes areas in these regions represent up to $30 \%$ of land surface (e.g. Walter et al., 2008) and this ratio could increase in the coming years, as permafrost degradation supports lakes development. These lakes, embedded in recently unfrozen sediments, sustain anaerobic condition favouring methane emissions. The latter have been largely studied in recent years (e.g. review Table in Walter et al., 2010), since they are recognized as an important contributor to the greenhouse effect. Nevertheless, $\mathrm{CH}_{4}$ emissions are still not included in Global Climate Models (GCMs) because of large uncertainties (IPCC, 2007; Koven et al., 2011).

Methane is produced within lake sediments as a results of acetate fermentation or $\mathrm{CO}_{2}$ reduction in anaerobic conditions. Methane reaches the atmosphere through the plants system, by bubbling or by diffusion through the water column. Bubbling is easily identified at lake surface and has been mainly studied during ice free periods using various techniques (e.g. floating chambers, bubble traps, inverted funnel systems) During winter periods, bubbles are enclosed in the ice indicating that methane emission from sediment is still an active process. In peculiar situations, the emissions are so intense that they inhibit the ice formation (hotspot). The transit in the water column can induce several biochemical reactions. Methane can be oxidized to $\mathrm{CO}_{2}$ in an oxic medium, via methanotrophic bacteria, and lakes can supply such an environment depending on their geometry and 
hydrology. Due to the temperature of the maximum of density of fresh water $\left(+4^{\circ} \mathrm{C}\right)$, lakes in periglacial areas are known as dimictic i.e. presenting two periods of stratification and two overturn events. The first overturning events happen at springtime, soon after ice cover melting, and the second one when the winter starts, before freeze in (Bastviken et al., 2004; Casper et al., 2000). Stratification favours the development of an anoxic layer whereas overturning causes oxygenation in the water column. Lakes are therefore mainly stratified during the winter and the ice cover will further limit atmosphere - water interactions. This closed system will result in the buildup of $\mathrm{CO}_{2}$ and $\mathrm{CH}_{4}$ concentrations in the water and mixing ratios in the ice. At spring melt, these gases will be released to the atmosphere within a few days (Michmerhuizen et al., 1996). Methane will resituate mainly from ice melting and bubbles emissions while carbon dioxide will release rather from gas diffusion as water overturns and equilibrates with the atmosphere (Casper et al., 2000; Michmerhuizen et al., 1996; Phelps et al., 1998). Indeed, the solubility of these two gases is very different: in fresh water at $20{ }^{\circ} \mathrm{C}$ pure $\mathrm{CH}_{4}$ saturation is about $1.6 \mathrm{~mol} \mathrm{~m}^{-3}$ whilst the $\mathrm{CO}_{2}$ saturation is reached at about $39 \mathrm{~mol} \mathrm{~m}^{-3}$. Moreover, lakes characteristics (size, depth, water circulation, hydrological system) should also influence gas emissions, a process which has only been scarcely described.

Most studies have performed measurements on open water and only a few have focused on the gas properties of the lake ice cover. Here we present, to our knowledge, the first high resolution profiles of the total gas content and gas composition of lake ice from 4 lakes in Northern Sweden. This approach enables us to discuss gas enclosure in lake ice during the 3 months period of ice growth prior to ice cores collection. In this pilot study, interactions between the water column and the ice cover as well as the intra- and inter-lake variability in hydrodynamic regimes are also shown to control bubbles composition, although a larger number of study cases is clearly required to quantitatively assess these relationships.

\section{Study area and sampling}

The four investigated lakes are embedded in the Stordalen Mire peat bog area $\left(68^{\circ} 21^{\prime} \mathrm{N}, 19^{\circ} 02^{\prime} \mathrm{E}\right)$, near the Torneträsk lake (Fig. 1). It is a sporadic or discontinuous permafrost area (Akerman and Johansson, 2008; Johansson et al., 2006a, b) with low vegetation (Sonesson et al., 1980; Svensson et al., 1999). Transects from the center to the bank have been performed for each lake, in order to study the intra-lake variability. Ice cores were extracted along these transects. Several of these were analyzed for their gas properties. In this paper, we present 3 cores from lake 2, and 4 cores from the other lakes. Figure 2 shows the ice cores locations, ice thickness and the depth profiles at times of core retrieval. We also collected about fifteen individual "ice embedded large flat bubbles".

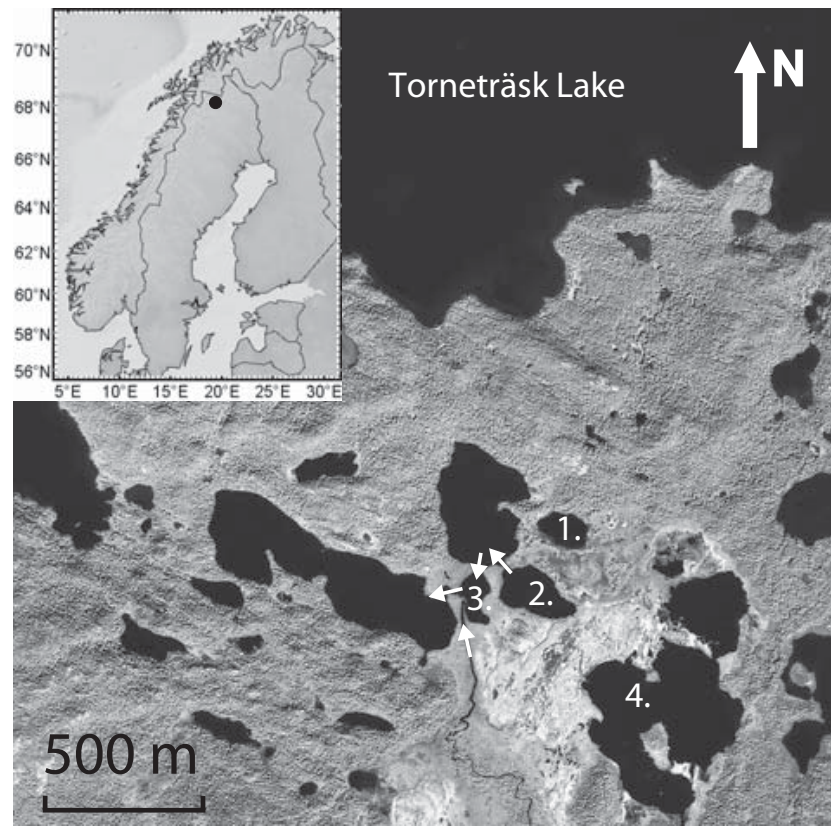

Fig. 1. Location map and lakes configuration (the arrows show water connections). The lakes are all embedded in a mire. lake 1, small and closed; lake 2, small and connected to another lake; lake 3 , small, receiving water from a river to the South, connected to another lake to the North and draining into another lake to the West; lake 4, bigger and closed.

These were ranging from 2 to $5 \mathrm{~cm}$ in diameter and were outcropping near the surface, but not especially along the studied transects. While lake 1 and lake 4 appear disconnected from any obvious water circulation pattern, lake 2 and lake 3 are not. We will refer to this contrast by using the "closed" vs. "open" lake terminology, respectively. lake 1, lake 2 and lake 3 display a small surface area of 0.01 to $0.02 \mathrm{~km}^{2}$. Lake 4 is quite larger $\left(0.19 \mathrm{~km}^{2}\right)$. According to water connections in the winter, lake 1 is closed. lake 2 has a semi-open character because of its connection to another lake downstream (see Fig. 1). Its profile hasn't been documented in details here, but its maximum depth is known to be $5 \mathrm{~m}$ (Kokfelt et al., 2009). lake 3 is relatively deep $(5 \mathrm{~m})$ for its size. It is an open system as it benefits from water fluxes throughout the winter. Incoming water originates from the river (see Fig. 1), and flows into the lake to the West (David Olefelt, personal communication, 2008). Lake 4 consists of three interconnected areas and seems to behave as a closed system. Only the southern area has been studied in this paper. There, the lake is shallow with a maximum depth of $105 \mathrm{~cm}$.

The lake ice was drilled at the end of the winter in the last days of March 2008, near to maximum ice thickness. 


\section{Methods}

The drilling was performed using a SIPRE-type ice auger $(7.5 \mathrm{~cm}$ in diameter), the samples were cut with a band saw in a $-20^{\circ} \mathrm{C}$ cold room. Horizontal thick sections $( \pm 8 \mathrm{~cm} \times 7 \mathrm{~cm} \times 0.5 \mathrm{~cm})$ were processed continuously along the ice cores using a Leitz 1400 microtome following the standard procedures from Langway (1958).

Gases entrapped in the ice were analysed every $5 \mathrm{~cm}$ (30 g-50 g) for their total volume and composition $\left(\mathrm{CO}_{2}, \mathrm{O}_{2}\right.$, $\mathrm{N}_{2}$ and $\mathrm{CH}_{4}$ ). Gas composition was measured by gas chromatography (Interscience Trace GC) using a FID detector for $\mathrm{CO}_{2}$ and $\mathrm{CH}_{4}$ and a TCD detector for $\mathrm{O}_{2}$ and $\mathrm{N}_{2}$. The gases were collected using the dry-extraction technique (extraction by crushing under vacuum $\left(10^{-3}\right.$ Torrs $)$ and at low $\left(-50^{\circ} \mathrm{C}\right)$ temperature) described in Raynaud et al. (1982) and Barnola et al. (1983). Precision of the measurements is $2.5 \%$ for $\mathrm{CO}_{2}, 0.4 \%$ for $\mathrm{O}_{2}$ and $\mathrm{N}_{2}$, and $3 \%$ for $\mathrm{CH}_{4}$.

Total gas content was determined using a Toepler pump, applying the melting-refreezing extraction technique described in Martinerie et al. (1994). This system consists in placing a cubic ice sample with length of about $4 \mathrm{~cm}$ into an hermetic vessel thoroughly evacuated $\left(10^{-3}\right.$ Torrs). The Toepler pump extracts, collects and measures the volume of all gases present in the vessel after the ice had been melted (hot water bath) and slowly refrozen from the bottom, in order to reject all gases during the new ice formation. The associated total gas volume error is $\leq 5 \%$ for ice containing small spherical bubbles as in glacier ice. This error can be largely increased for cylindrical bubbles (as observed in lake ice) since part of them can be open by cross-cutting during the sample preparation. The amount of gas lost can be estimated using calculation developed in Martinerie et al. (1990) and is depending of the length, width and spacing of the cylindrical bubbles. In our case, the proportion of loss from the cylindrical bubbles varies between $20 \%$ and $90 \%$ for bubbles lengths of $0.6 \mathrm{~cm}$ and $3.2 \mathrm{~cm}$ respectively.

Ice thickness and depth measurements were performed with an ice thickness gauge designed (precision: $\pm 1 \mathrm{~cm}$ ) by Kovacs, an American company specialized in ice drilling and coring equipment.

\section{Results}

\subsection{Ice characteristics}

Figure 3 summarizes the ice and bubbles morphology from the 15 studied ice cores, as seen in transmitted light through the $0.5 \mathrm{~cm}$ thick sections. Visually, bubble shapes show a large variability. However, 6 major ice types have been identified from bubble characteristics. Type 1 is peculiar and scarce, we call it "snow ice", because this ice type results from liquid water infiltration and refreezing in the snow cover at the lake surface. We observed this ice type at the
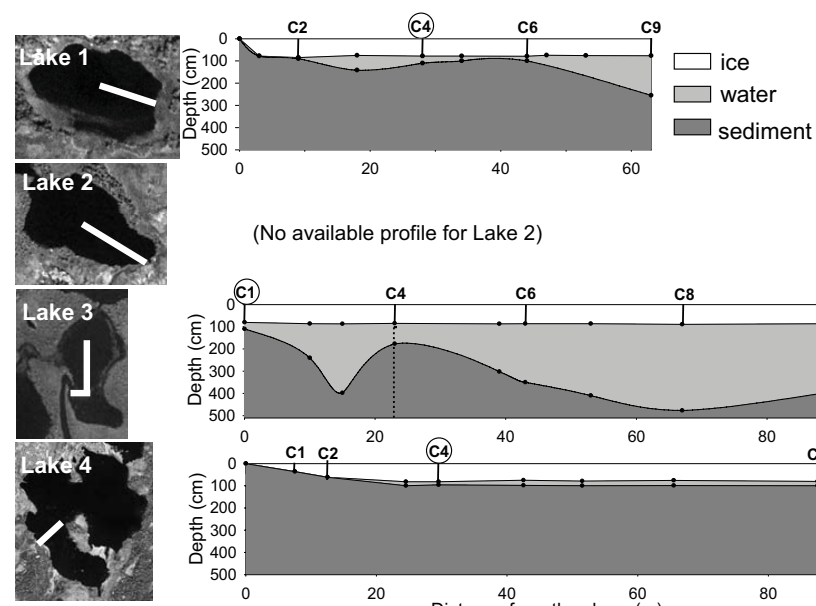

(No available profile for Lake 2)
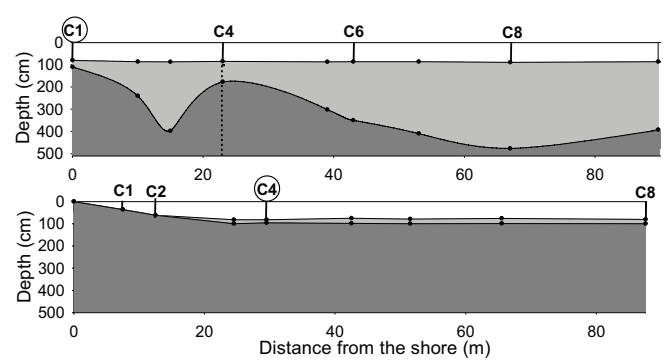

Fig. 2. Lakes geometry along the profiles and ice core sampling locations. The white line on lakes shows the transect direction, letters and numbers correspond to the cores studied for the bubbles morphology and circles indicate cores analyzed for their gas properties. The dotted line in the lake 3 profile shows the change of azimuth of the transect.

very top of core 1 on lake 3 . Type 2 corresponds to ice without visible bubbles. We will refer to it as "clear ice", and it has been found in most part of the lake 3 ice cover but also in small sections of lake 1 and lake 2 cores. Ice with elongated cylindrical bubbles (ice type 3 ) is predominant in lake 4 (e.g. around $40 \mathrm{~cm}$ depth) but also in some sections of lake 1 and lake 2. Ice with spherical or nut shape bubbles is found at the bottom of all the shallow depths cores of lake 1 . Note that this ice type 4 is quite rich in bubbles.

Some core sections clearly display a mixture of cylindrical, spherical, and nut shaped bubbles as for example, section $47-65 \mathrm{~cm}$ depth in core 6 of lake 1 . This fifth ice type is called "mixed ice". Finally, as described earlier in the paper, we can sometimes observe a sixth ice type which contains bigger isolated large flat bubbles (see, top of core 2 in lake 1). These bubbles can be very large with a diameter of up to a meter and are generally filled up by small hexagonal ice crystals, giving a whitish appearance to the bubble. These crystals, resulting probably from the inverse sublimation process after bubbles formation, reduce the gas volume in the latter. In this work, the maximum bubble size analyzed was obviously constrained by the corer diameter.

The genesis of the various ice types described above will be discussed further in this paper, but we would like to emphasize at this stage how the spatial distribution of these ice types varies within each lake as well as in between them. In lake 1, the bubble content drastically increases between 50 $\mathrm{cm}$ depth and the bottom of cores 2, 4 and 6 where we find ice type 4 and 5. This feature does not exist in core 9, sampled above deeper water (Fig. 2), where the bottom part is made of "clear ice" (ice type 2). Of all lakes studied, lake 3 


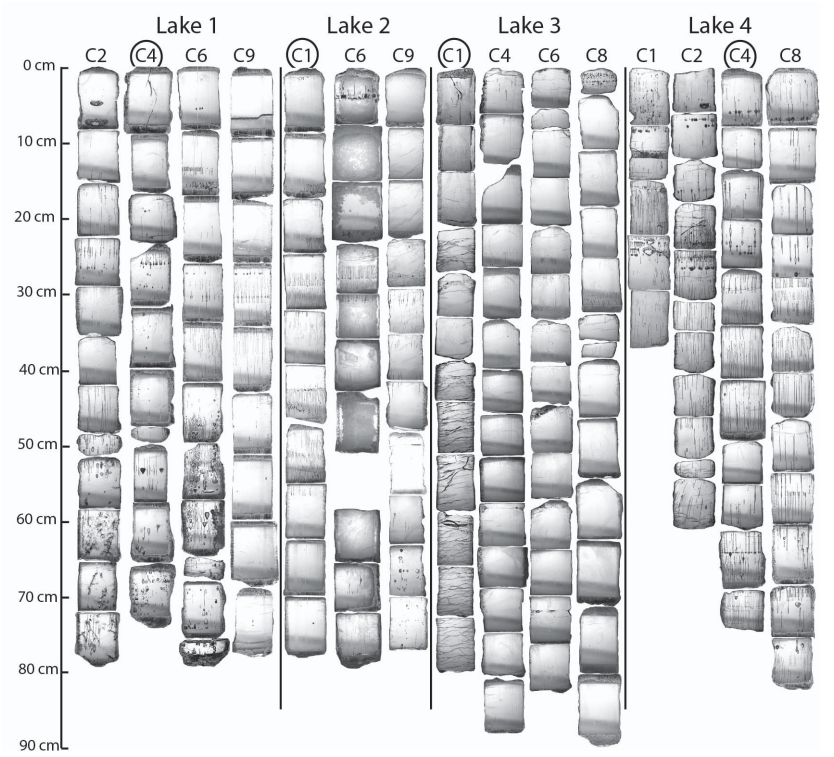

Fig. 3. Ice characteristics, bubbles shapes and distribution in the 15 studied ice cores (see Fig. 2 for location). Circles denote the cores analyzed at high resolution for their gas properties.

shows the lowest bubble density. It predominantly consists of ice type 2 (clear ice) except for two discrete zones with cylindrical elongated bubbles (around $30 \mathrm{~cm}$ depth and at the top of core 8) (Fig. 3). The sub horizontal lines in core 1 from the same lake are not bubble but natural fractures. Lake 4 , which is nearly frozen to bottom along the whole profile (Fig. 2), on the contrary, shows a large density of bubbles for all cores at all depths, dominated by ice type 3 (elongated bubbles) and mixed ice (ice type 5). Finally, in all of the 15 ice cores for which thick sections have been made, we can identify a common zone of higher bubble density at about $30 \mathrm{~cm}$ depth (Fig. 3).

\subsection{Gas composition}

Spatially continuous gas composition measurements have been performed at high resolution $(5 \mathrm{~cm})$ in a selected core of each lake (cores 4, 1, 1 and 4 for respectively lakes 1,2,3 and 4). We also measured the gas composition within the individual large flat bubbles of ice type 6 . Results are presented in Fig. 4.

Methane mixing ratios (Fig. 4a) vary largely between 3 ppm and $47 \%$. Large flat bubbles show the maximum mixing ratios whereas profiles values are at the level of tens to hundreds of ppm with a few peaks around 10 to $20 \%$. We observe an increase for all lakes (except for lake 3 ) around $25 \mathrm{~cm}$ depth. Methane mixing ratios for lakes 1 and 4 increase with depth whereas the mixing ratios of lakes 2 and 3 remain low.

Unlike methane, the range of $\mathrm{CO}_{2}$ mixing ratios (Fig. 4b) is the same for the large flat bubbles (ice type 6) as for the
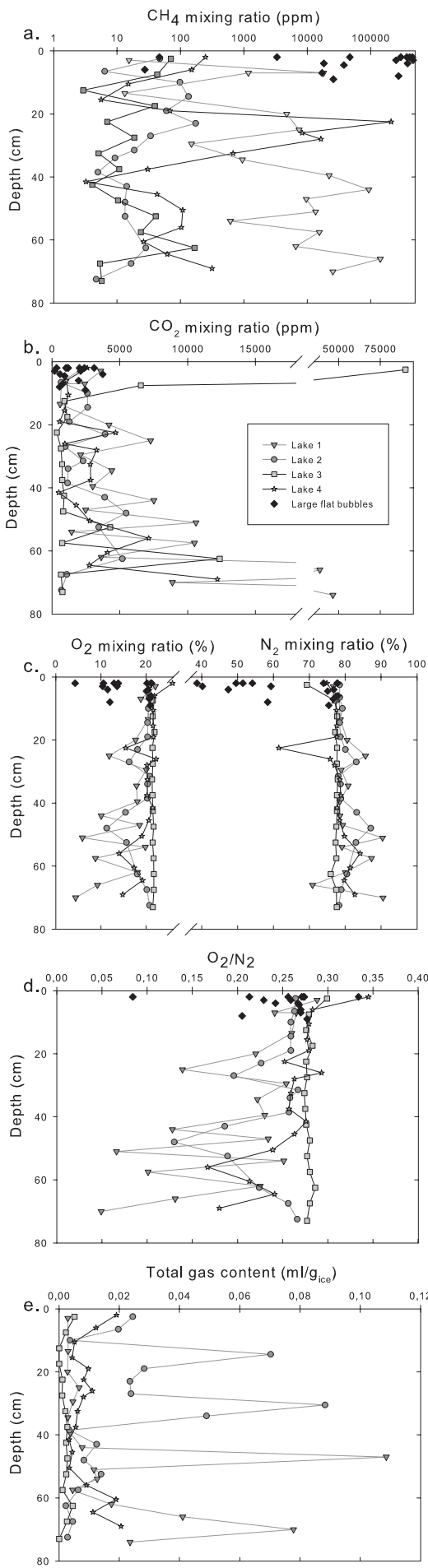

Fig. 4. Gas composition and total gas content versus depth for one core of each of the four studied lakes and for fifteen isolated bubbles sampled near the ice surface. A logarithmic scale has been chosen for $\mathrm{CH}_{4}$. Note that the total gas content is not presented for the isolated bubbles (see text for details). 
cores profiles (between 200 and $4000 \mathrm{ppm}$ ). One exception is snow ice at the very top of lake $3(9 \%)$. For all lakes, however, the $\mathrm{CO}_{2}$ mixing ratio increases with depth with a maximum value of $46600 \mathrm{ppm}$.

Oxygen mixing ratio (Fig. $4 \mathrm{c} \mathrm{left)} \mathrm{is} \mathrm{about} 20 \%$ near the surface of all lakes, to the exception of some large flat bubbles with lower values at $10 \%$. In lake 1,2 and 4 , there is also a relative minimum at $10-15 \%$ around $25 \mathrm{~cm}$ depth and a clear decrease again between $40 \mathrm{~cm}$ depth and the bottom of the cores to mixing ratios of 5 to $15 \%$. lake 3 , on the contrary, is remarkably stable at a value of $21 \%$, close to the atmospheric value, although with very low total gas content (see Fig. 4e and Sect. 4.3.).

Nitrogen mixing ratios (Fig. 4c right) are around $78 \%$ near the lakes surface and, in most cases, logically evolve as mirror-image of the $\mathrm{O}_{2}$ mixing ratio (since these two species are dominant in the mix).

The $\mathrm{O}_{2} / \mathrm{N}_{2}$ ratio (Fig. 4d) varies between 0.084 and 0.33 for ice type 6 and between 0.26 and 0.34 for the cores profiles near the lakes surface. The ratio decreases with depth to a minimum value of 0.05 for lakes 1,2 and 4 whereas it remains constant for lake 3 with a value of 0.28 . The decrease of the ratio actually always reflects a decrease in the oxygen, which is confirmed by a comparison of $\mathrm{O}_{2}$ and $\mathrm{N}_{2}$ concentrations in the water (not shown). For lake 1, 2 and 4 repeated changes of the ratio are seen throughout the depth, superimposed to the general trend.

\subsection{Total gas content}

The total gas content results of Fig. 4e should generally be considered as minimum values. As discussed in the method section, the extraction process indeed underestimates the total gas content from the samples, by cutting through bubbles on sampling and therefore losing part of their gas content. This error becomes significant for ice with cylindrical elongated bubbles (between $20 \%$ and $90 \%$ for bubbles length about $0.6 \mathrm{~cm}$ and $3.2 \mathrm{~cm}$ respectively) and it is difficult to determine the ratio of each bubble length for a given sample.

This being said, our values are in the same range or slightly higher than other studies previously performed on lake ice (e.g. Lorrain et al., 1999, 2002). Note also that values above the maximum equilibrium dissolved gas content of fresh water (about $0.023 \mathrm{ml} \mathrm{g}_{\text {ice }}^{-1}$ ) are also observed in lakes 1 and 2 .

We do not show values for ice type 6 since this has no meaning (single isolated bubbles).

\section{Discussion}

\subsection{A new lake ice type classification based on bubbles properties}

Bubble formation processes and shapes in lake ice have already been discussed at length by several authors (Adams et al., 1998; Bari and Hallett, 1974; Carte, 1961; Gow and
Langston, 1977). These authors suggest that bubble shapes and density result from a balance between ice growth rate and diffusion of rejected gases in the liquid reservoir ahead. As the ice grows, most of the gases remain dissolved in the water since gas solubility in ice is at least 2 order of magnitude smaller than in water (Killawee et al., 1998). With a faster freezing front, bubbles will form and be rather elongated and perpendicular to the ice front. They can sometimes be accompanied by "nut shape" bubbles. At low freezing rates, the ice can be devoid of bubbles if the expulsed gases are able to diffuse and dissolve in the water reservoir. Finally another type of bubbles is commonly encountered in lake ice covers of permafrost areas. It originates from sediment degassing (Walter et al., 2006) and consists of large flat bubbles trapped within the ice as it grows around.

The data collected in this paper enable us to propose a new "process-driven" lake ice type classification based on bubbles characteristics and associated gas composition. This classification, summarized in Fig. 5, combines the influence of dissolved gases in the water, sediment degassing and gaswater interactions within the water column. It differs from the one established by Walter et al. (2006), mostly by the bubble size range that we address. Indeed, in this work, we are limited by the sampling method to bubbles that are smaller than $5 \mathrm{~cm}$ in diameter. Each of the 6 ice types described in Sect. 4 and Fig. 5 can then be associated to a specific genetic process for the bubble inclusions. Type 1 (snow ice) is formed by liquid water infiltration in blown snow at the surface of the lake and subsequent refreezing. Type 2 (clear ice) is typical of lake ice formed in conditions of slower freezing (favouring diffusion ahead of the freezing front) of a water reservoir which is undersaturated or not supersaturated enough for bubble nucleation to take place. Type 3 (elongated bubbles) and 4 (spherical and nuts shape bubbles) is typical lake ice where bubbles solely result from the capture of exsoluted gases as the boundary layer at the ice-water interface gets strongly supersaturated from impurity rejection by the ice (higher freezing rates, closed system freezing). Type 6 ice (large flat bubbles) is the signature of an ebullition process from the sediment on the lake floor, captured at the base of the ice cover. Finally, type 5 is the expected mixed facies when both exsolution and ebullition contribute to the bubble content at the same location.

\subsection{Depth dependency of the gas composition}

In parallel with the different bubble characteristics of the various ice types, the composition of these gaseous inclusions varies with depth in most cases. Figure $4 \mathrm{c}$, for example, shows a clear decrease of the oxygen mixing ratio from $20 \%$ near the surface to about 5 to $10 \%$ at $70 \mathrm{~cm}$ depth. Simultaneously, the $\mathrm{CO}_{2}$ mixing ratio increases from 500$1500 \mathrm{ppm}$ up to a maximum value of $40000 \mathrm{ppm}$. Oxygen depletion with depth is a known phenomenon in stratified 

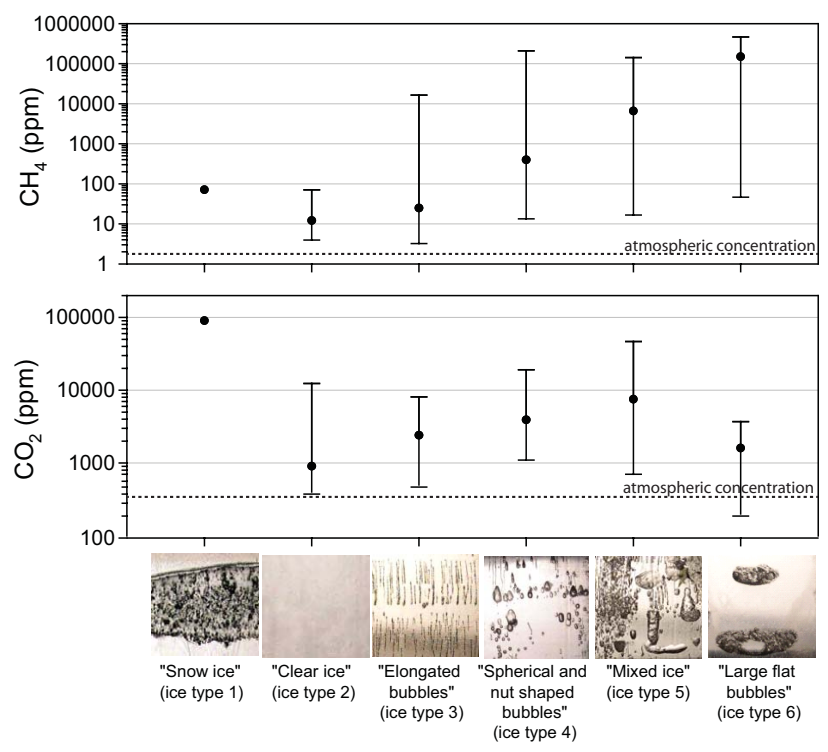

Fig. 5. Ice types classification from bubble shapes and density, with associated ranges of $\mathrm{CO}_{2}$ and $\mathrm{CH}_{4}$ mixing ratios. Note the logarithmic mixing ratio scale. Black dots are median values and vertical bars represents the variability in the observations.

lakes (e.g. Casper et al., 2000) and generally attributed to respiration processes.

In order to decipher the impact of biogeochemical processes from the mere physical evolution of gas properties under the specific hydrodynamic conditions of a freezing lake, we have estimated the evolution of gas concentration in water $\left(\mathrm{moll}^{-1}\right)$ and of gas mixing ratios $(\mathrm{ppm}, \%)$ in water and ice, using the simple following approach. We hypothesize that the initial gas composition of the lake water is in equilibrium with the atmosphere for $\mathrm{O}_{2}, \mathrm{~N}_{2}$ and $\mathrm{CH}_{4}$ and showing a $p \mathrm{CO}_{2}$ of $600 \mathrm{ppm}$ as measured by Jonsson et al. (2007) in early autumn for lakes in our study area. We further assume, that the reservoir evolves as a closed system and that no supersaturation persist for a significant period of time before bubbles nucleation takes place. We then compute, using Henry's law (Eq. 1) and the total gas content measured in the ice (Fig. 4e), the theoretical evolution of gas concentrations $\left(\mathrm{moll}^{-1}\right)$ in the water reservoir with depth at all times applying a simple mass balance between ice and water (Fig. 6). This is shown as white diamonds for oxygen, carbon dioxide and methane in Fig. 7 (nitrogen not shown).

$c=k_{\mathrm{h}} \times p$

Where $c=$ dissolved gas concentration $\left(\mathrm{moll}^{-1}\right)$

$$
\begin{aligned}
& k_{\mathrm{h}}=\text { Henry's constant }\left(\mathrm{mol} \mathrm{1}^{-1} \mathrm{~atm}^{-1}\right) \\
& p=\text { gas partial pressure }(\mathrm{atm})
\end{aligned}
$$

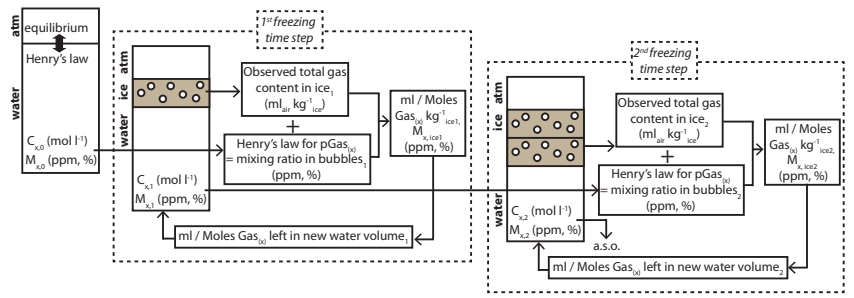

Fig. 6. Conceptual diagram for the calculations performed to reconstruct theoretical gas concentrations and mixing ratios in ice an water in the case of a closed system reservoir in which gases are considered as passive tracers (no biogeochemical transformations). $\mathrm{C}=$ concentration in water, $\mathrm{M}=$ mixing ratio in the water, $0=$ initial water, $1=1$ st freezing step, $2=2$ nd freezing step, a.s.o = repetition of the process. Specific calculation in the case of carbon dioxide, taking into account the carbonate system equilibria, are detailed in the text.

$k_{\mathrm{h}}$ values and temperature corrections were applied as recommended in Sander's review (1999). Further, theoretical mixing ratios in water and ice (using Henry's law again) can be reconstructed (Fig. 6), as shown for all gases in Fig. 8.

A specific approach has been adopted in the case of carbon dioxide to take into account the evolution of the carbonate system as freezing occurs. Observed autumnal ranges (Jonsson et al., 2007) of $p \mathrm{CO}_{2}$ (around $600 \mathrm{ppm}$ ) and of total dissolved inorganic carbon (DIC - around $100 \mu$ moles $\mathrm{g}^{-1}$ ) have been used in the USGS version of the $\mathrm{CO} 2 \mathrm{Calc}$ program (Robbins et al., 2010) to assess the initial alkalinity (TA) of the water reservoir before freezing. $\mathrm{CO} 2 \mathrm{Calc}$ was then used iteratively to recalculate equilibrium $p \mathrm{CO}_{2}$ (and therefore mixing ratio in the newly formed bubbles) from updated TA and DIC at each freezing step, taking into account the amount of DIC stored as $\mathrm{CO}_{2}$ bubbles in the newly formed ice. Used settings for the $\mathrm{CO} 2 \mathrm{Calc}$ program were: salinity $=0 \%$, temperature $=0{ }^{\circ} \mathrm{C}$, Pressure $=1 \mathrm{~atm}, \mathrm{~K} 1$ and $\mathrm{K} 2$ from Millero 1979, $\mathrm{KHSO}_{4}=$ Dickson, $\mathrm{pH}$ scale $=$ NBS scale.

This theoretical model is clearly a simple theoretical reference scenario treating gases as passive tracers in that: (a) no water mass advection from other lakes is allowed, (b) bubbles nucleation is occurring as soon as maximum solubility is reached, (c) selective diffusion ahead of the freezing front is neglected (which might affect the mixing ratios by a maximum factor of 2 to 3 in the early stages of freezing (high freezing rates, top layers) and (d) surmised homogeneization of the gas rejected in the reservoir will be potentially partly hampered due to the temperature-driven density stability of the water column (increasing the potential supersaturation at the ice-water interface). Note however that the latter should not affect our results since we use the observed total gas contents in the ice (as opposed to a parametrization of ex-soluted gases from the level of supersaturation) and since the potential absence of physical mixing should affect all gases in the 

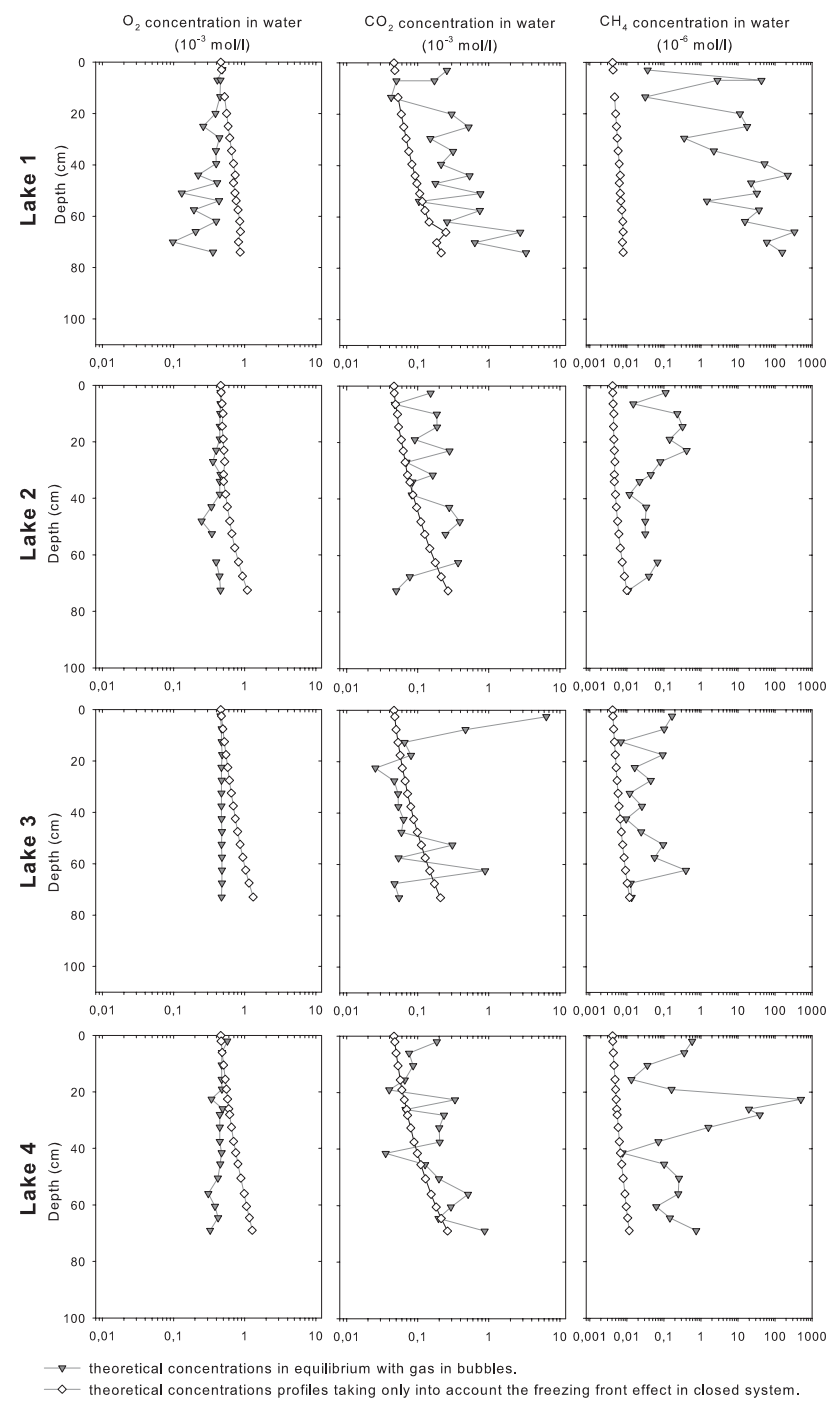

Fig. 7. Theoretical $\mathrm{O}_{2}, \mathrm{CO}_{2}$ and $\mathrm{CH}_{4}$ concentrations in water as a function of depth for each lake: triangles represent values in equilibrium with measured gas mixing ratios in bubbles (calculated using Henry's law); diamonds show theoretical values calculated by only taking into account the "reservoir effect" in a closed system (see text for details).

same way (therefore not altering the mixing ratios deduced from gas concentrations in the new water volume - Fig. 6).

Despite these limitations, our theoretical curves of Figs. 7 and 8 allow us to put forward potential discrepencies due to either open system conditions or biogeochemical processes.

As expected from the limited amount of gas enclosed as bubbles in the ice, theoretical concentrations in water regularly increase with depth (Fig. 7, $\mathrm{N}_{2}$ not shown). Also, following relative solubilities, mixing ratio increase for all gases but nitrogen, as as nitrogen is the dominant and least soluble species (Fig. 8a). Maximum theoretical water concentrations are reached at the bottom of lake 1 with value of $5.0 \mathrm{ppm}$ in

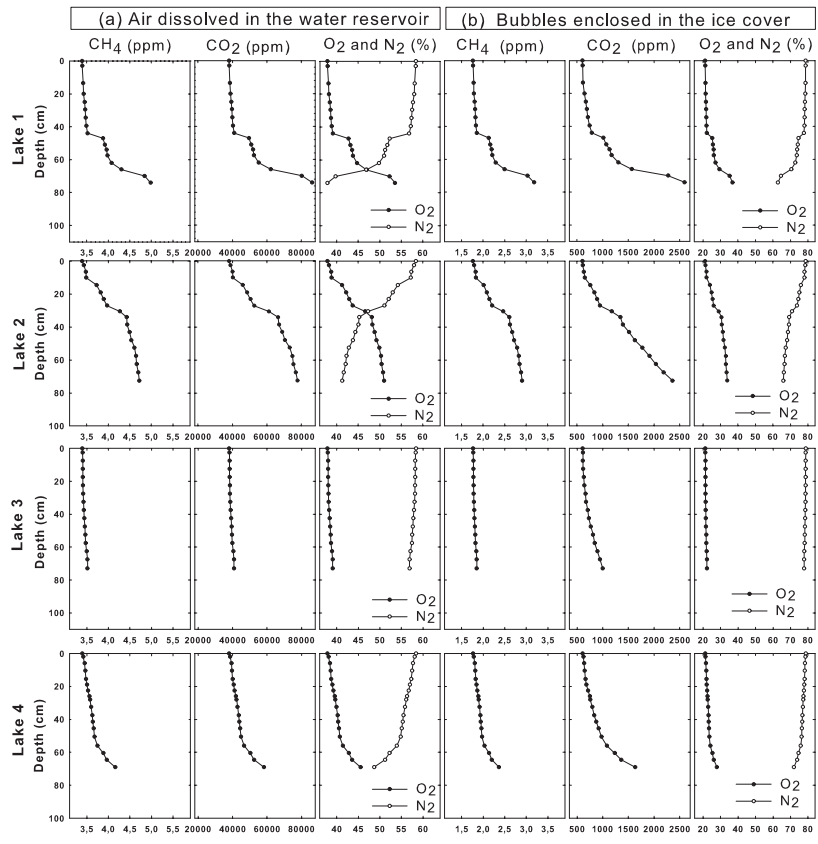

Fig. 8. Theoretical evolution of mixing ratios for (a) air dissolved in water and (b) bubbles in ice, assuming lakes are closed reservoir, using observed total gas contents and equilibrium mixing in water from Henry's law for mass balance in the ice and assuming no gas fractionation occurs at the ice water interface (see text for details).

$\mathrm{CH}_{4}, 86000 \mathrm{ppm}$ in $\mathrm{CO}_{2}$ and $54 \%$ for $\mathrm{O}_{2}$, resulting in ice bubbles mixing ratios of $3.2 \mathrm{ppm}, 2600 \mathrm{ppm}$ and $36.9 \%$, respectively. Another salient feature of Fig. 8 is the behavior of lake 3 showing only little changes with depth, as expected from its deeper waters (Fig. 2).

Real gas concentrations in the water can also be reconstructed using the measured gas mixing ratios in the ice and applying Henry's law. This is shown for $\mathrm{O}_{2}, \mathrm{CO}_{2}$ and $\mathrm{CH}_{4}$ as grey triangles in Fig. 7.

Are the observed ice gas mixing ratio profiles of Fig. 4 then coherent with the closed system theoretical evolution shown in Fig. 8b? Methane shows a wide range of values (from a few ppm to 100000 ) and no systematic increasing trend with depth. Only exceptionally is the maximum "closed system" value of a few ppm observed (here as a minimum in the profiles), and not necessary at the bottom of the ice cover. This clearly suggests that exsolution is not the dominant process in controlling methane mixing ratios in the ice, but rather the varying contribution of ebullition process.

Comparing observed to theoretical profiles for carbon dioxide in lakes 1, 2 and 4 shows a similar trend of increasing mixing ratio in ice (Fig. 8b) and concentrations in water (Fig. 7, middle panel). However, again, in both cases, observed values can be higher than theoretical ones by up to an order of magnitude, with considerable superimposed variability. An additional source of carbon dioxide is therefore 
required, and this from the very beginning of the growth season as shown by the lake water supersaturation level of the reconstructed water concentrations from bubbles in the ice (Fig. 7, central panel). Could this be the result of respiration processes in the reservoir? The behavior of dissolved oxygen is worth considering in that respect. Indeed, instead of showing the expected increase of mixing ratio (Fig. 8a) and concentration in water (Fig. 7, left panel, white diamonds) with depth, reconstructed water concentrations actually slightly decrease in lakes 1,2 and 4 . This could be interpreted as the signature of respiration. Looking at relative increase of $\mathrm{CO}_{2}$ and decrease of $\mathrm{O}_{2}$ in Fig. 7 reveals important contrasts between lakes and between depths in a given lake. In the lower half of lakes 2 and 4 oxygen loss and $\mathrm{CO}_{2}$ gain are in relative balance, which does not preclude a respiration control in the water column during ice growth. On the contrary, in the upper half of the ice cover from the same lakes, negligible amounts of oxygen are lost, whilst excess carbon dioxide is present. For lake $1, \mathrm{CO}_{2}$ gain is at all times in excess of the $\mathrm{O}_{2}$ loss, also suggesting an alternative source to respiration for $\mathrm{CO}_{2}$, from the very beginning of the lake ice growth. Finally, lake 3, which has been described as a relatively open system, shows three distinct sections; a lower one coherent with episodic respiration processes and returns to a fully open system regime, a top section where the $\mathrm{CO}_{2}$ gain overwhelms the (negligible) $\mathrm{O}_{2}$ loss (as in all other lakes), and a middle section where $\mathrm{CO}_{2}$ concentrations are again what would be expected from open system conditions.

To summarize, dissolved $\mathrm{CO}_{2}$ concentrations in the waters of lakes 2, 3 and 4 could be explained by "in situ" respiration processes for waters generating the lower part of the lake ice cover (late growth), whilst an extra source (as compared to simple equilibrium with atmosphere) is needed for the waters generating the upper part of the lake ice cover (early growth). For lake 1, this extra source is needed at all times. Although reservoir closure is unable to explain the observed levels of water concentration, it could be partly responsible for the general trend of $\mathrm{CO}_{2}$ concentrations in lakes 1,2 and 4.

Several mechanisms, other than respiration, could be responsible for the high levels of observed dissolved $\mathrm{CO}_{2}$ in our lake waters. Gas ebullition from the sediment can certainly contribute to the $\mathrm{CO}_{2}$ increase. Sulfato-reduction, which is often associated to the methanogenesis process (Fenchel et al., 1998), is also a provider of carbon dioxide. The particular smell of $\mathrm{H}_{2} \mathrm{~S}$, another by product of the reaction, has been detected in the course of sampling. Denitrification, methane oxidation or acetate fermentation can also contribute to the $\mathrm{CO}_{2}$ content (Stumm and Morgan, 1996). In our case, the similarity of the reconstructed $\mathrm{CH}_{4}$ and $\mathrm{CO}_{2}$ concentration profiles in water in most lakes (Fig. 7, middle and right panels) suggest that acetate fermentation might be the dominant extra $\mathrm{CO}_{2}$ source at work, as opposed to methane oxidation. This also puts forward acetate fermentation as the source for methane. $\delta^{13} \mathrm{C}$ and $\delta \mathrm{D}$ isotopic analysis of the
$\mathrm{CH}_{4}$ would of course help in deciphering the sources, but these unfortunately and not available at this time. The generalized $\mathrm{CO}_{2}$ excess in the surface layer of all lakes could reflect the dynamical instability of the lake waters in the autumn, bringing bottom enriched waters to the lake surface just before the onset of freezing.

The $\mathrm{O}_{2} / \mathrm{N}_{2}$ ratio (Fig. $4 \mathrm{~d}$ ) reflects the changes in the oxygen mixing ratio and can therefore be used as an indicator of the stratification process in the lake during the winter. However, it can also be a measure of the hydrological regime in the lake (open vs. closed system). For example, lake 3 shows a constant $\mathrm{O}_{2} / \mathrm{N}_{2}$ ratio throughout the depth because the input of atmosphere equilibrated waters from the river upstream (Fig. 1) inhibits the changes in oxygen mixing ratios due to the ice cover freeze on (closure) or biological processes as discussed above. It is interesting to note that local $\mathrm{CO}_{2}$ mixing ratio increases occur at about 50 and $60 \mathrm{~cm}$ depth, despite the water circulation. This suggests that these excursions correspond to local ebullition events, as confirmed in the $\mathrm{CH}_{4}$ profile.

\subsection{Ice type dependency of gas mixing ratios}

Figure 5 shows contrasted $\mathrm{CH}_{4}$ and $\mathrm{CO}_{2}$ signatures for the various ice types described in Sect. 5.1. Only one measurement is available for the "snow ice" (type 1), and it shows the highest $\mathrm{CO}_{2}$ value of the whole study at $90000 \mathrm{ppm}$. This is hard to explain by physical processes only. Figure 8 a shows that $\mathrm{CO}_{2}$ values up to $86000 \mathrm{ppm}$ can be reached for gas dissolved in water during closed system freezing of lake reservoir (at about $70 \%$ freezing). Bulk freezing of residual water from the final stages of closed system freezing of a lake, expelled at the surface through the moat and bathing the snow cover, could therefore lead to such high $\mathrm{CO}_{2}$ values. This is however quite unlikely, since our "snow ice" was measured at the surface of lake 3, which was the least "closed". Bacterial respiration of organic matter blown with the snow at the lake ice surface is another plausible explanation. Strangely enough, oxygen does not show the expected concentration decrease if aerobic respiration had been active. Ice types 2 to 4 should span the range of theoretical $\mathrm{CO}_{2}$ mixing ratios shown in Fig. $8 \mathrm{~b}$ (600 to $2600 \mathrm{ppm}$ ) if the water was initially with a $p \mathrm{CO}_{2}$ about $600 \mathrm{ppm}$. We know from the discussion above that this is not true, and the observed range of 3000 to $4000 \mathrm{ppm}$ is in accordance with ex-solution from a lake water displaying the observed excess- $\mathrm{CO}_{2}$ concentration. The "mixed ice" (type 5), with apparent contribution from both exsolution bubbles and small bubbles resulting from sediment ebullition, shows higher $\mathrm{CO}_{2}$ and $\mathrm{CH}_{4}$ mixing ratios as compared to ice type 3 and 4 . This suggests that the small bubbles coming from the sediment contribute to increase both the carbon dioxide and the methane content as surmised from the discussion in the previous section. The large flat bubbles (type 6), also derived from sediment ebullition are globally richer in methane but poorer in carbon dioxide. This 
however does not mean that the amount of carbon dioxide in these bubbles is lower as compared to ice type 5, since the data are shown as mixing ratio (i.e. relative concentration). It is nevertheless disturbing, if ice type 5 is a mixture between ice types $3 / 4$ and 6 , that the $\mathrm{CO}_{2}$ mixing ratio is not at an intermediate value (as does $\mathrm{CH}_{4}$ in Fig. 5). This suggests that a small fraction of methane (not detectable in Fig. 7) might have been oxidized to $\mathrm{CO}_{2}$ in the lake environment. Finally, it is striking that, although they show an increasing mean/median methane concentration value, ice types 4,5 and 6 display similar (large) concentration ranges. This probably reflects the combination of increased supersaturation of the ex-soluted waters in the nearly closing reservoir (ice type 4) and direct ebullition from the sediment nearby (ice type 6).

Our results globally underline that the lake ice cover signature is far from being governed by pure ebullition only. As illustrated by the contrast between ice type 5 and 6 , the least soluble methane dominates ebullition, while carbon dioxide mixing ratio is higher in the lake ice storage. Clearly, our data indicate that exsolution dominates the lake ice cover signature. Further, the fact that methane mixing ratios observed in bubble type 6 , the closest to pure ebulliton, are still largely lower than those observed in studies of pure ebullition fluxes, indicates that substantial exchanges with dissolved gases occurred for those ice entrapped ebullition products. This however needs to be weighed, in terms of budget, by the overwhelming amount of gas liberated through ebullition, as compared to the one stored in the lake ice.

\subsection{Controls on bubble distribution in lake ice}

Intra-lake and inter-lake comparison in our dataset shows that there is a control of geometry on the bubble distribution in the ice, which is of potential interest in the perspective of upscaling regional dataset to global carbon budgets. For instance, the proximity of the bottom of the lake increases the amount of bubbles in the ice. Figures 2 and 3 indeed show that the lower part of cores C2, C4 and C6 of lake 1 (in shallow areas) is rich in bubbles while core C9 (located above deeper waters) is not. Lake 4 is shallow and nearly frozen to the bottom and its ice cores are bubble rich. This suggests that shallow lakes will enclose more gas in the ice cover. Other factors such as the amount of organic matter locally available or the sedimentation rate would of course further affect the gas fluxes from the sediment, but these were not documented in the present data set.

The hydrological regime of the lake system can also directly impact the gas content in the lake ice. Our study shows that if a lake is part of an open drainage system, the ice can be nearly devoid of gas. Lake 3, which is fed by a river (Fig. 1), and where the water drains into another lake, is a good example (Fig. 3). The three other lakes, on the contrary, are closed or open to another lake without significant water circulation and all show a significative bubble content. In the first case it would be adequate to investigate if the lack of bubbles in the ice is counterbalanced by a supplementary provision in the connected lakes, and to understand how they will affect the quantity (fluxes) and the quality $\left(\mathrm{CH}_{4}\right.$ vs. $\left.\mathrm{CO}_{2}\right)$ of the gases released to the atmosphere.

The proximity of the lake banks does not seem, in our data set, to affect the bubble distribution despite the fact that lakes can be more methane productive along lakes margins (e.g. Walter et al., 2007). However, all lakes are relatively small, and the situation might be different for larger lakes. Local events of atmospheric pressure drop has also been claimed to trigger bubble production in lake ice (Mattson and Likens, 1990; Semiletov, 1999). In this study, we observed two simultaneous bubbling events for the 4 lakes, the first one around $30 \mathrm{~cm}$ depth (well documented in Fig. 3) and the second around $60 \mathrm{~cm}$ (clearly seen during cores handling). To investigate a potential relationship of these events to marked atmospheric pressure changes, we first need to reconstruct a time line for the buildup of the lake ice cover. A simple (neglecting geothermal heat flux) thermodynamic model for freezing (Hinkel, 1983) has been run, based on Eq. (2):

$p_{i} \lambda \frac{\partial Z_{\mathrm{i}}}{\partial t}=\frac{T_{0}-T_{\mathrm{s}}}{\frac{Z_{\mathrm{i}}}{K_{\mathrm{i}}}+\frac{Z_{\mathrm{s}}}{K_{\mathrm{s}}}}$

Where $\rho_{\mathrm{i}}=$ density of ice $\left(\mathrm{kg} \mathrm{m}^{-3}\right)$

$$
\begin{aligned}
& \lambda=\text { latent heat of fusion }\left(\mathrm{J} \mathrm{kg}^{-1}\right) \\
& Z_{\mathrm{i}}=\text { ice thickness }(\mathrm{m}) \\
& Z_{\mathrm{S}}=\text { snow thickness }(\mathrm{m}) \\
& K_{\mathrm{i}}=\text { thermal conductivity of ice }\left(\mathrm{W} \mathrm{m}^{-1}{ }^{\circ} \mathrm{C}^{-1}\right) \\
& K_{\mathrm{S}}=\text { thermal conductivity of snow }\left(\mathrm{W} \mathrm{m}^{-1}{ }^{\circ} \mathrm{C}^{-1}\right) \\
& T_{0}=\text { temperature at ice/water interface }\left({ }^{\circ} \mathrm{C}\right) \\
& T_{\mathrm{S}}=\text { surface temperature }\left({ }^{\circ} \mathrm{C}\right) \\
& t=\text { duration of constant } \mathrm{T}_{\mathrm{S}}(s)
\end{aligned}
$$

The model reconstructs the ice thickness $Z_{\mathrm{i}}$ as a function of temperature from the first day of freezing. It has been run both with and without a snow cover to obtain a reasonable prediction of the evolution of the ice cover. The snow cover data set from the nearby weather station doesn't account for snow redistribution at the surface of the lakes. Therefore the model has been run both with and without a snow cover to obtain a reasonable prediction of the evolution of the ice cover. From those runs, we have correlated in Fig. 9 (hatched area) the observed major bubbling events at around 30 and $60 \mathrm{~cm}$ depth with major occurrences of atmospheric pressure 


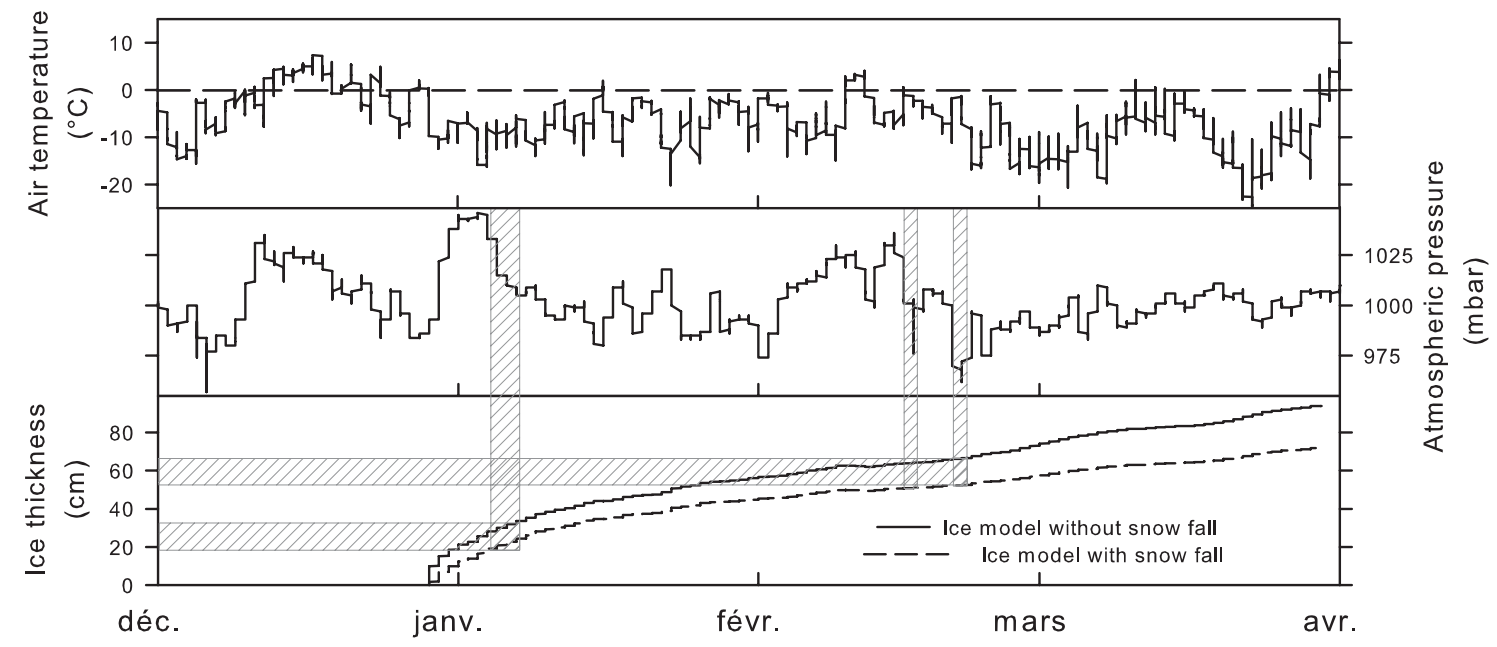

Fig. 9. Air temperature and atmospheric pressure versus modelled ice thickness from Eq. (2) (see text). The dotted line takes snow falls into account. Shadow hatchings show depth fitting with the air pressure drop events. The two highlighted drops correspond with the depth of the two synchronous bubbling events described in the text.

drops. This confirms that attention should be drawn to major atmospheric pressure events in assessing methane release efficiency from boreal lakes.

\subsection{Assessing a lower bound for lake ice melting contribution to the atmospheric methane budget}

In this section we present a "back of the envelope" calculation for a minimum winter contribution of periglacial lakes to methane fluxes to the atmosphere. We rely on our ice type/bubbles classification to perform a budget for methane accumulation in lake ice during the winter. We first calculate the proportion of each ice type in each core considering it as representative for the whole lake ice cover. We then multiply this proportion by the minimum, mean (median) and maximum $\mathrm{CH}_{4}$ mixing ratio for this type of ice and by the observed mean total gas content of the given ice type. This provides an ice-type weighed concentration of methane in $\mathrm{ml}$ $\mathrm{CH}_{4}$ per gram of ice for each lake. This value is then integrated over the lake ice mass and divided by the lake area and by the number of days the ice cover existed. Results are presented in Table 1. Although these values do not represent the actual flux of methane to the atmosphere during the relatively short melting period, they provide a mean winter daily flux, that can be more easily compared to spring-summer flux estimates available in the literature.

We consider these values as minimal for two reasons: (a) because the total gas volume measurements were probably biased towards gas losses (see Subsect. 4.3), and (b) because we cannot include the contribution of bubbles above 5 to $6 \mathrm{~cm}$ in diameter, which are most likely the larger contributors to the methane budget (Walter et al., 2010). We however consider our results as a measure of
Table 1. Bounds for methane fluxes released by the winter lake ice cover. The median value is used if the mean value is higher than the standard deviation.

\begin{tabular}{llll}
\hline $\begin{array}{l}\text { Methane fluxes } \\
\left(\mathrm{mg} \mathrm{CH}_{4} \mathrm{~m}^{-2} \mathrm{~d}^{-1}\right)\end{array}$ & Minimum & Mean or median & Maximum \\
\hline lake 1 & $1.34 \times 10^{-3}$ & 3.01 & 12.7 \\
lake 2 & $3.91 \times 10^{-4}$ & $4.32 \times 10^{-2}$ & 4.4 \\
lake 3 & $6.52 \times 10^{-5}$ & $4.35 \times 10^{-4}$ & $1.14 \times 10^{-2}$ \\
lake 4 & $3.59 \times 10^{-4}$ & $3.21 \times 10^{-2}$ & 4.22 \\
\hline
\end{tabular}

the "background contribution" of permafrost lake ice; without the big bubbles events. This work is therefore complementary to other studies focusing on large methane emission observed in spring, due to the ice cover melting and water turnover which releases the excess dissolved gases stored in the water column (Michmerhuizen et al., 1996; Phelps et al., 1998). It is also complementary to studies focusing on larger bubbles in winter lake ice (e.g. Walter et al., 2006, 2007, 2008, 2010).

Our results present a large variability between each lake. Lake 1 shows values $\left(1.34 \times 10^{-3}-12.7 \mathrm{mg} \mathrm{CH}_{4} \mathrm{~m}^{-2} \mathrm{~d}^{-1}\right)$ comparable to other studies (Bastviken et al., 2004; Kling et al., 1992; Repo et al., 2007; Rudd et al., 1993; Zimov et al., 2001) reporting values from 0.3 to $77 \mathrm{mg} \mathrm{CH}_{4} \mathrm{~m}^{-2} \mathrm{~d}^{-1}$. Lakes 2,3 and 4 , on the contrary, show values from $6.52 \times 10^{-5}$ to $4.4 \mathrm{mg} \mathrm{CH}_{4} \mathrm{~m}^{-2} \mathrm{~d}^{-1}$ which are in the lowest range of those reported in most studies on methane fluxes from lakes (values observed from 0 to $3240 \mathrm{mg} \mathrm{CH} 4 \mathrm{~m}^{-2} \mathrm{~d}^{-1}$; Walter et al., 2010). We did expect to find moderate contribution from lake ice in the winter, but we show here that these are not negligible and worth considering in global budget estimations. 


\section{Conclusions}

This work contributes to the study of methane released from lakes in periglacial environments. It provides new results on the winter gas storage associated to the lake ice cover buildup. A new genetic lake ice types classification is proposed, based on bubbles shapes, density and gas composition. It is used to provide a first minimal estimate of methane fluxes associated to winter storage in the lake ice cover, which are complementary to previous studies focusing on spring and summer fluxes from open water sources and studies focusing on large bubbles in lake ice. It is shown that although moderate, as expected, these fluxes are not negligible with respect to other sources.

Gas composition study of the bubbles reveals strong supersaturation of the lake water both in methane and carbon dioxide, especially in the lakes that evolve in near closed system. These high concentrations are thought to mainly result from interaction with biological processes in the sediment, of which acetate fermentation would be a likely candidate, given the observed synergy between $\mathrm{CO}_{2}$ and $\mathrm{CH}_{4}$ in the profiles. Part of the excess $\mathrm{CO}_{2}$ could also result from respiration processes, as indicated by oxygen losses, especially during the second half of the ice growth period. Mere closure of the lake reservoir cannot explain the observed concentration excess, but could be partly responsible for the global trend of increasing concentrations with depth in the water and in the ice.

We also demonstrated that lakes geometry and hydrological regime affect the amount and characteristics of gases enclosed in the ice, although this pilot study obviously does not have yet the statistical power to derive quantitative relationships. Finally, we confirm that atmospheric pressure regimes can trigger bubble nucleation and sediment ebullition events and therefore should be considered as a factor in methane release efficiency.

Future work will focus on the stable isotope composition of the bubbles in the different ice types, in order to decipher the relative importance of physico-chemical and biologically mediated processes in controlling the gas properties in permafrost lake ice.

Acknowledgements. We thank the Abisko Scientific Research Station (ANS) in Sweden for their grant and the weather data, the "Fonds de Service pour la Recherche Glaciologique Polaire de l'Université Libre de Bruxelles" and the "Crédits pour Brefs Séjours à l'étranger" of the FNRS for the financial support. We thank Kristina Bäckstrand and David Olefelt for their field knowledge and the personal communications.

Edited by: T. J. Battin

\section{References}

Adams, E. E., Priscu, J. C., Fritsen, C. H., Smith, S. R., and Brackman, S. T.: Permanent ice covers of the McMurdo Dry Valleys lakes, Antarctica: bubble formation and metamorphism, in Ecosystem Dynamics in a polar desert: the McMurdo Dry Valleys, Antarctica, edited by: Priscu, J., American Geophysical Union, Washington, DC., 281-295, 1998.

Akerman, H. J. and Johansson, M.: Thawing Permafrost and Thicker Active Layers in Sub-arctic Sweden, Permafrost Periglac., 19, 279-292, 2008.

Bari, S. A. and Hallett, J.: Nucleation and growth of bubbles at an ice-water interface, J. Glaciol., 13, 489-520, 1974.

Barnola, J. M., Raynaud, D., Neftel, A., and Oeschger, H.: Comparison of $\mathrm{CO}_{2}$ measurements by two laboratories on air from bubbles in polar ice, Nature, 303, 410-413, 1983.

Bastviken, D., Cole, J., Pace, M., and Tranvik, L.: Methane emissions from lakes: Dependence of lake characteristics, two regional assessments, and a global estimate, Global Biogeochem. Cy,, 18, GB4009, doi:10.1029/2004GB002238, 2004.

Carte, A. E.: Air bubbles in ice, Proceedings of the Physical Society, 77, 757-768, doi:10.1088/0370-1328/77/3/327, 1961.

Casper, P., Maberly, S. C., Hall, G. H., and Finlay, B. J.: Fluxes of methane and carbon dioxide from a small productive lake to the atmosphere, Biogeochemistry, 49, 1-19, 2000.

Fenchel, T., King, G. M., and Blackburn, T. H.: Bacterial biogeochemistry: The Ecophysiology of mineral cycling, Academic Press, 1998.

Gow, A. J. and Langston, D.: Growth history of lake ice in relation to its stratigraphic, crystalline and mechanical structure, USA CRREL Report (Cold Regions Research and Engineering Laboratory), 77, 24, 1977.

Hinkel, K. M.: Ice-cover growth rates at nearshore locations in the Great Lakes, NOAA Tech. Memorandum ERL GLERL, 35, 34 pp., 1983.

IPCC: Intergovernmental Panel on Climate Change (IPCC), the physical science basis, Cambridge Univ. Press, 996 pp., 2007.

Johansson, M., Christensen, T. R., Åkerman, H. J., and Callaghan, T. V.: What determines the current presence or absence of permafrost in the Torneträsk region, a sub-arctic landscape in northern Sweden?, Ambio, 35, 190-197, 2006a.

Johansson, T., Malmaer, N., Crill, P. M., Friborg, T., Akerman, J. H., Mastepanov, M., and Christensen, T. R.: Decadal vegetations changes in a northern peatland, greenhouse gas fluxes and net radiative forcing, Glob. Change Biol., 12, 2352-2369, 2006b.

Jonsson, A., Åberg, J., and Jansson, M.: Variations in $p \mathrm{CO}_{2}$ during summer in the surface water of an unproductive lake in northern Sweden, Tellus B, 59, 797-803, 2007.

Juutinen, S., Rantakari, M., Kortelainen, P., Huttunen, J. T., Larmola, T., Alm, J., Silvola, J., and Martikainen, P. J.: Methane dynamics in different boreal lake types, Biogeosciences, 6, 209223, doi:10.5194/bg-6-209-2009, 2009.

Killawee, J. A., Fairchild, I. J., Tison, J.-L., Janssens, L., and Lorrain, R.: Segregation of solutes and gases in experimental freezing of dilute solutions: Implications for natural glacial systems, Geochim. Cosmochim. Ac., 62, 3637-3655, 1998.

Kling, G., Kipphut, G., and Miller, M.: The flux of $\mathrm{CO}_{2}$ and $\mathrm{CH}_{4}$ from lakes and rivers in arctic Alaska, Hydrobiologia, 240, 2336, 1992.

Kokfelt, U., Rosén, P., Schoning, K., Christensen, T. R., Förster, J., 
Karlsson, J., Reuss, N., Rundgren, M., Callaghan, T. V., Jonasson, C., and Hammarlund, D.: Ecosystem responses to increased precipitation and permafrost decay in subarctic Sweden inferred from peat and lake sediments, Glob. Change Biol., 15, 16521663, doi:10.1111/j.1365-2486.2009.01880.x, 2009.

Koven, C. D., Ringeval, B., Friedlingstein, P., Ciais, P., Cadule, P., Khvorostyanov, D., Krinner, G., and Tarnocai, C.: Permafrost carbon-climate feedbacks accelerate global warming, PNAS, 108, 14769-14774, 2011.

Langway, C. C. J.: Ice fabrics and the Universal stage, 62, 16 pp., 1958.

Lorrain, R. D., Fitzsimons, S. J., Vandergoes, M. J., and Stievenard, M.: Ice composition evidence for the formation of basal ice from lake water beneath a cold-based Antarctic glacier, Ann. Glaciol., 28, 277-281, 1999.

Lorrain, R., Sleewaegen, S., Fitzsimons, S., and Stievenard, M.: Ice formation in an Antarctic glacier-dammed lake and implications for glacier lake interactions, Arct. Antarct. Alp. Res., 34, 150 158, 2002.

Martinerie, P., Lipenkov, V. Y., and Raynaud D.: Correction of aircontent measurements in polar ice for the effect of cut bubbles at the surface of the sample, J. Glaciol., 36, 299-233, 1990.

Martinerie, P., Lipenkov, V. Y., Raynaud, D., Chappellaz, J., Barkov, N. I., and Lorius, C.: Air content paleo record in the Vostok ice core (Antarctica): A mixed record of climatic and glaciological parameters, J. Geophys. Res., 99, 10565-10576, 1994.

Mattson, M. D. and Likens, G. E.: Air pressure and methane fluxes, Nature, 347, 718-719, 1990.

Michmerhuizen, C. M., Striegl, R. G., and McDonald, M. E.: Potential Methane Emission from North-Temperate Lakes Following Ice Melt, Limnol. Oceanogr., 41, 985-991, 1996.

Phelps, A. R., Peterson, K. M., and Jeffries, M. O.: Methane efflux from high-latitude lakes during spring ice melt, J. Geophys. Res., 103, 29029-29036, 1998.

Raynaud, D., Delmas, D., Ascencio, J. M., and Legrand, M.: Gas extraction from polar ice cores: a critical issue for studying the evolution of atmospheric $\mathrm{CO}_{2}$ and ice-sheet surface elevation, Ann. Glaciol., 3, 265-268, 1982.

Repo, M. E., Huttunen, J. T., Naumov, A. V., Chichulin, A. V., Lapshina, E. D., Bleuten, W., and Martikainen, P. J.: Release of CO2 and $\mathrm{CH}_{4}$ from small wetland lakes in western Siberia, Tellus B, 59, 788-796, doi:10.1111/j.1600-0889.2007.00301.x, 2007.
Robbins, L. L., Hansen, M. E., Kleypas, J. A., and Meylan, S. C.: CO2calc-A user-friendly seawater carbon calculator for Windows, Max OS X, and iOS (iPhone), US Geological Survey Open-File Report 2010, 1280, 17, 2010.

Rudd, J. M., Harris, R., and Kelly, C. A.: Are hydroelectric reservoirs significant sources of greenhouse gases?, Ambio, 22, 246248, 1993.

Sander, R.: Compilation of Henry's Law Constants for Inorganic and Organic Species of Potential Importance in Environmental Chemistry, version 3, 107 pp., 1999.

Semiletov, I. P.: Aquatic Sources and Sinks of $\mathrm{CO}_{2}$ and $\mathrm{CH}_{4}$ in the Polar Regions, J. Atmos. Sci., 56, 286-306, 1999.

Sonesson, M., Jonsson, S., Rosswall, T., and Rydén, B. E.: The Swedish IBP/PT Tundra Biome Project Objectives-PlanningSite, Ecol. Bull., 30, 7-25, 1980.

Stumm, W. and Morgan, J. J.: Aquatic Chemistry: Chemical Equilibria and Rates in Natural Waters, 3rd Edn., Wiley-Interscience., 1996.

Svensson, B. H., Christensen, T. R., Johansson, E., and Öquist, M.: Interdecadal Changes in $\mathrm{CO} 2$ and $\mathrm{CH} 4$ Fluxes of a Subarctic Mire: Stordalen Revisited after 20 Years, Oikos, 85, 22-30, 1999.

Walter, K. M., Zimov, S. A., Chanton, J. P., Verbyla, D., and Chapin, F. S.: Methane bubbling from Siberian thaw lakes as a positive feedback to climate warming, Nature, 443, 71-75, doi:10.1038/nature05040, 2006.

Walter, K. M., Smith, L. C., and Stuart Chapin, F.: Methane bubbling from northern lakes: present and future contributions to the global methane budget, Philos. T. R. Soc. A, 365, 1657-1676, 2007.

Walter, K. M., Chanton, J. P., Chapin, F. S., Schuur, E. A. G., and Zimov, S. A.: Methane production and bubble emissions from arctic lakes: Isotopic implications for source pathways and ages, J. Geophys. Res., 113, G00A08, doi:10.1029/2007JG000569, 2008.

Walter, K. M., Vas, D. A., Brosius, L., Chapin III, F. S., Zimov, S. A., and Zhuang, Q.: Estimating methane emissions from northern lakes using ice-bubble surveys, Limnol. Oceanogr.-Meth., 8, 592-609, 2010.

Zimov, S. A., Voropaev, Y. V., Davidov, S. P., Zimova, G. M., Davidova, A. I., Chapin III, F. S., and Chapin, M. C.: Flux of methane from North Siberian aquatic systems: Influence on atmospheric methane, in: Permafrost response on economic development, environmental security and natural resources, edited by: Paepe, $\mathrm{R}$. and Melnikov, V., 511-524, 2001. 